\title{
Learners' attitudes towards the recognition and development of isiBhaca in the education space in Umzimkhulu, KwaZulu-Natal, South Africa
}

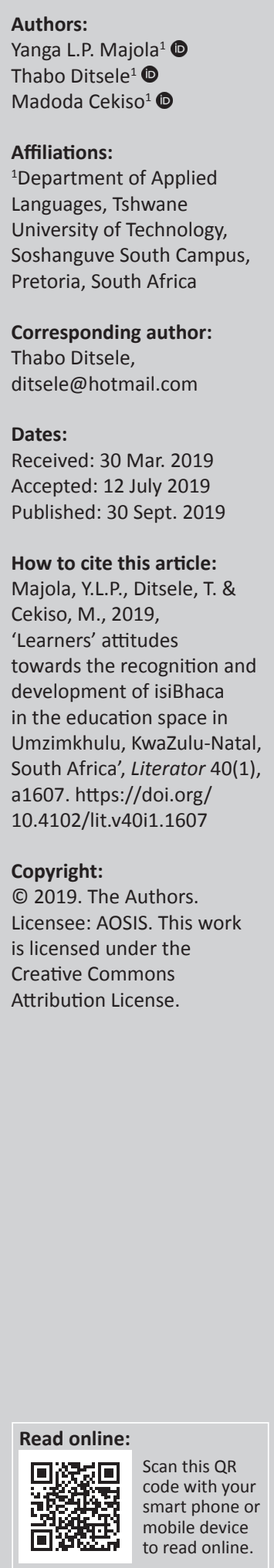

Attitudes towards varieties of a language have been an issue in educational contexts. For example, it is generally said that societies have a positive attitude towards the standard variety and a negative attitude towards the non-standard varieties of a language. The attitudes towards language varieties can affect their use in education and can have an impact on learners' learning and achievement. In some contexts, learners hold a view that dialect-speaking learners have lower academic potential than learners speaking the standard dialect. The learners' attitudes have significant implications for the use of dialects in the classroom as it can determine the value and emphasis given to the dialect in education. Therefore, this article establishes the attitudes held by learners towards the recognition and development of isiBhaca in the education space in Umzimkhulu. Using mixed methods, the study followed a survey research design. Data were gathered from 128 purposively selected learners from Grades 6 and 7 at six schools in Umzimkhulu. Mean scores about the belief statements were calculated in order to analyse the quantitative data, whereas the qualitative data were analysed thematically. The study found that learners held positive attitudes towards the recognition and development of isiBhaca in the education space, although they were unsure as to whether this recognition should extend to the language being given official status in the provinces of KwaZulu-Natal and the Eastern Cape, where it has a significant number of home language speakers.

Keywords: Language attitudes; non-official language; isiBhaca; education; KwaZulu-Natal.

\section{Introduction}

Foley (2001) argues that despite the fact that the South African Constitution (Act No. 108 of 1996) guarantees learners the right to receive education in the language of their choice, there are some very real difficulties involved in the implementation of the new national language policy in South Africa. This challenging situation is made worse by the fact that there are variations within languages. Therefore, Tegegne (2015) argues that linguistic diversity is not only limited to multilingualism, but there are also variations within the same language. These variations are also called dialects, which are defined as sub-classes or varieties within a language. In addition, Tegegne (2015) is of the view that attitudes towards varieties of a language have been an issue in educational contexts. For example, it is generally said that societies hold a positive attitude towards the standard variety and a negative attitude towards the non-standard varieties (Tegegne 2015).

Babich (1987) points out that the important feature that unites dialects within a general language group is that while speakers of different dialects somewhat differ from one another, they can still understand each other. The findings of the study conducted by Cheshire (2005) revealed that the varieties of a language play an important role in educational context and, as such, in this connection, learning is claimed to be better and more successful when conducted in the variety spoken by students. Tegegne (2015) supports this idea when he claims that the use of a variety of language preferred by students in education enables students to use their own potential and helps them achieve deep learning. It is against this background that the current study focuses on the learners' attitudes towards the recognition and development of isiBhaca as a medium of instruction (MOI) in the education space in Umzimkhulu, KwaZulu-Natal. The current study is conceived against the background that the non-standard language learners bring to school from their environment is absolutely not accommodated; instead, the standard language is strongly favoured and serves as a MOI. In such cases, the learner is faced with two different situations in school with standard language and society with a non-standardised dialect (Gxilishe 1996). 
People who identify themselves as members of the following tribes - Xhosa, Thembu, Xesibe, Ntlangwini, Gcaleka, Bomvana, Mpondomise, Mpondo, Hlubi, Cele, and Bhaca - are all classified as amaXhosa and are presumed to be home language (HL) speakers of isiXhosa, which has official status in South Africa. In Umzimkhulu, isiXhosa and/or isiZulu are taught to HL speakers of isiBhaca. While the two languages are mutually intelligible with isiBhaca, HL speakers of isiBhaca do not ordinarily speak isiXhosa and/or isiZulu at home or when they socialise among themselves. For example, the dialect of isiBhaca differs from standard isiXhosa in terms of vocabulary; for instance, in isiXhosa, 'African beer' is called utywala, while in isiBhaca, it is ijiki; 'to run' in isiXhosa is ukubaleka, while in isiBhaca, it is ukugijima.

The role of dialect in education has been the focus of research by local scholars, Mtsatse and Combrinck (2018); Maqam (2015); Spofana (2011); Sigcau (1998); Gxilishe (1996) and Nomlomo (1993). Specifically, debates over how to teach learners who primarily speak a non-standard dialect, like isiBhaca, came to the forefront of educational concerns. The most advanced among the arguments is that although it is important to educate learners in a standard dialect, the schooling system should not ignore the language skills and dialects that learners possess when entering the classroom, as learners understand the world through their dialect (Kramer 2004). While several studies focus on the dilemma of dialect in the classroom (Gxilishe 1996; Nomlomo 1993), only a few studies, such as by Spofana (2011), focus on the attitudes of learners towards recognition of their dialect in the classroom. Moreover, Mtsatse and Combrinck (2018) declare that literature on the influence of dialect use in the classroom in the South African context is limited to mostly postgraduate studies. Therefore, there is a great need for the current study in order to understand learners' attitudes towards the recognition and development of isiBhaca in the education space. Having this information is likely to empower teachers on how to use learners' non-standard dialect as a bridge to standard language and also to promote learners' self-image and sense of belonging.

\section{Research questions}

This study sought to establish learners' attitudes towards the recognition and development of isiBhaca for learning purposes in Umzimkhulu. To achieve the study's objectives, we will seek to establish the following:

- Whether learners hold positive or negative attitudes towards the introduction of isiBhaca in their education.

- Whether learners believe that the introduction of isiBhaca in their education would be beneficial or detrimental to their education, as opposed to the retention of isiXhosa and isiZulu in their education.

- Whether they are conscious about language rights as they pertain to isiBhaca being recognised and developed for the purposes of learning.

\section{Literature review Language as an identity}

Identity is about how individuals or groups see and define themselves and how other individuals or groups see and define them (Dumitraskovic 2014). Dumitraskovic (2014) further points out that identity is formed through the socialisation process and the influence of social institutions, such as the family, the education system and mass media.

Research has shown that learners' first language is the optimal language for literacy and learning throughout primary school (Ball 2014; UNESCO 2008). In addition, Cummins (2000) claims that learners often have a sense of identity and agency when their mother tongue is valued and used in school as MOI. Ball (2010:13) defines MOI as the language which is used for instruction in or out of school to teach the basic curriculum of the educational system. While many studies advocate for the use of the child's mother tongue as a MOI (Butzkamm 2003; Malone 2007), there has been a considerable controversy regarding the use of dialect in the classroom (Gxilishe 1996).

\section{Standard language and dialect}

Sailzmann (2007) defines the standard dialect as a prestigious, codified variety that has the highest social status and is used in formal occasions. On the other hand, Cook (2003) defines the non-standard dialect as any variety of language that is not standardised and lacks prestige. In addition, Downes (1998) points out that sometimes the standard variety is considered as a language, whereas the non-standard variety is considered as a dialect. Adding to the hegemony of the standard language over dialect, Dunstan (2015) states that the standard language is typically based on the dominant class's values. Lippi-Green (2012) argues that as language and identity are inextricably tied, to reject a person's language is to reject that person and their culture. Moreover, Dunstan (2015) argues that while educators attempt to recognise and promote awareness of diversity of race, gender, ethnicity, nationality and religion in the classroom, diversity of language is often not seen as a type of diversity for scholars and educators to learn about and celebrate, but as an issue that requires homogenisation and standardisation. Papapavlou and Pavlou (2007) declare that linguists know that the designation of a linguistic code as a language or dialect is usually based on socio-historical and political criteria rather than on purely linguistic ones. These authors are of the view that even if local dialects do not directly fall under the category of regional and minority languages, they should be treated with the same respect that is bestowed to standard or official languages.

\section{Using dialect in the classroom}

Dumitraskovic (2014) points out that although several countries in Europe have successfully dealt with the use of dialects in education, in other countries such matters are yet to be adequately addressed and effectively resolved. 
Papapavlou and Pavlou (2007) argue that it is common practice in bi-dialectal speech communities that standard dialects are strongly favoured in education, whereas the role of the non-standard dialects in education is highly disputed. According to Papapavlou and Pavlou (2007), this is due to the fact that some educators are still debating whether dialects should be used in education because, among other concerns, they erroneously question the adequacy of dialects in meeting speakers' communicative needs. The use of dialects in the classroom has been recommended by some scholars, such as Papapavlou and Pavlou (2007), who argue that the potential use of non-standard dialects in education could contribute to the elevation of the status of non-standard dialects in a speech community and prevent their decay and possible extinction. On the other hand, Gxilishe (1996) is of the view that the issue of whether or not to use pupils' non-standard variety in the classroom is controversial. As the South African Language in Education Policy (Republic of South Africa 1996) recommends multilingualism, Gxilishe (1996) views the situation as a fertile ground for the introduction of dialects in the classrooms. Gxilishe (1996) states that there are two arguments for the use of dialect in the classroom. Gxilishe (1996) declares that on the one hand dialects may be useful as a bridge to standard language and on the other hand their initial use could be beneficial in promoting the child's self-image and sense of belonging. Supporting the use of dialects in the classroom, Tegegne (2015) points out that the use of learners' native dialect in education enhances the social, cognitive, emotional and linguistic development of learners in and out of school. Therefore, it is appropriate that learners are educated through their dialect.

\section{Language attitudes}

Perloff (1993:26) suggests that one should first deal with the concept of attitude before moving on to language attitudes. Garrett, Coupland and Williams (2003:03) point out that an 'attitude' is constituted of three parts; it is structured in a cognitive, affective and behavioural manner. Attitudes are cognitive because they contain or comprise beliefs about the world; they are affective because they involve feelings about an object; and they are systematically linked to behaviour because they predispose us to act in a certain way. Therefore, language attitudes can be defined as negative or positive feelings towards a particular language and the behaviour the speakers of a particular language have towards that language. Particular cultural groups have a major role in attitudes people may have towards a particular language, and also the particular stereotypes speakers of the language have towards it may be resulting in negative language attitudes (Giles \& Johnson 2006:38). Ajzen (1988:4) points out that language attitudes may be defined as emotional attitudes, and would be the nature and manner which people use to respond favourably or unfavourably to a particular object, human being or event. According to Tegegne (2015), the attitudes towards language varieties can affect their use in education and can have an impact on students' learning and achievement.

\section{Methodology}

This research employed an explanatory mixed-method approach, that is, quantitative data were analysed first, followed by qualitative data. Johnson and Turner (2003) state that the combined use of qualitative and quantitative approaches complements both and paints a clearer picture of the research problem. The study used a survey research design. McMillan and Schumacher (2010:22) state that in a survey research design, the investigator selects a sample of subjects and administers a questionnaire or conducts interviews to collect data. They further point out that surveys are used to describe attitudes, beliefs, opinions and other types of information.

The study sample comprised 128 respondents who were purposively selected from Grades 6 and 7 at schools identified as ideal for the study. Creswell and Plano Clark (2011) are of the view that 'purposive sampling' involves identifying and selecting individuals or groups of individuals that are especially knowledgeable about or experienced with a phenomenon of interest. Apart from knowledge and experience, Bernard (2002) highlights the importance of availability and willingness to participate and the ability to communicate experiences and opinions in an articulate, expressive and reflective manner.

Self-developed closed- and open-ended questions were used to gather data from the respondents. With regard to closedended questions, 12 Likert-type scale statements were put before the respondents and they were asked to mark the option which best suited them from the following five options: (1) strongly disagree or SD; (2) disagree or D; (3) not sure or NS; (4) agree or A; and (5) strongly agree or SA. To determine their 'aggregate attitudinal tendencies' using 'mean scores', the scales which appear in Table 1 were used.

We deemed 'mean scores' and not a deeper statistical analysis (e.g. standard deviation) to be adequate for reaching conclusions on 'aggregate attitudinal tendencies' because more emphasis was placed on qualitative data as opposed to quantitative data.

Ethical clearance was obtained. Before the data-gathering phase, learners' parents and guardians signed informed consent forms while learners assented. All the respondents (as well as parents and guardians) were guaranteed that codes would be used to ensure that their identities were protected.

TABLE 1: Scalar units, scores and aggregate attitudinal tendencies.

\begin{tabular}{lcl}
\hline Scalar units & Scores & Aggregate attitudinal tendencies \\
\hline $4.50-5.00$ & 5 & Strongly agree \\
$3.50-4.49$ & 4 & Agree \\
$2.50-3.49$ & 3 & Not sure \\
$1.50-2.49$ & 2 & Disagree \\
$1.00-1.49$ & 1 & Strongly disgree \\
\hline
\end{tabular}

Source: Ditsele, T., 2014, 'Perceptions of Black South African languages: A survey of the attitudes of Setswana-speaking university students toward their first language', Doctoral thesis, Tshwane University of Technology, Pretoria 


\section{Ethical consideration}

Ethical clearance was issued by Tshwane University of Technology's Research Ethics Committee on 19 March 2016, with ethical clearance number FCRE/APL/STD/2016/03.

\section{Findings and discussions}

IsiBhaca was spoken by an overwhelming majority of the respondents $(79.7 \%)$ and that rendered 'home language' as an unusable variable because the other two languages, isiXhosa and isiZulu, comparatively had too low percentages. That left 'sex', 'age' and 'school' as the three variables that were used for data analysis.

\section{Quantitative data}

To achieve the study's objectives, 12 Likert-type scale belief statements, which were put before 128 learners, were split into the following three categories: (1) Using isiBhaca in the education space; (2) Recognising and developing isiBhaca; and (3) Matching isiBhaca against isiXhosa and isiZulu. For each category, 'mean scores' and 'aggregate attitudinal tendencies' were presented in tables, followed by an analysis of individual belief statements, and lastly, a summary of each category.

\section{Category 1: Using isiBhaca in the education space}

Belief statements 5, 6, 8 and 11 belong to this category and are presented in Table 2 .

Belief statement 5: isiBhaca is only relevant for discussing matters such as lobola negotiations and not for educational purposes.

This belief statement scored a 'mean' of 2.20, which means that the respondents disagreed with it. Put differently, they believed that isiBhaca could be developed for educational purposes.

Both male $($ mean $=2.38)$ and female $($ mean $=2.05)$ respondents disagreed with the belief statement. The oldest respondents (14 years old) recorded a 'mean score' of 1.20, thus strongly disagreed with the belief statement, while the other two groups disagreed with it (13 year old $=2.13$ and 12 years old $=2.28$ ).

Belief statement 6: Learners in Umzimkhulu perform poorly in school because they are taught in isiXhosa or isiZulu, and not in isiBhaca.
In this belief statement, the respondents recorded a 'mean score' of 3.96. This indicates that they agreed with the belief statement. The respondents may be having a few challenges with understanding content through isiXhosa and that would explain why they believed isiBhaca could help improve school performance.

Female $($ mean $=4.08)$ and male $($ mean $=3.75)$ respondents agreed with the belief statement. The oldest group (14 years old) with a 'mean score' of 5.00 strongly agreed with the belief statement, while the other two groups agreed with it (13 year old $=3.92$ and 12 years old $=3.82$ ).

Belief statement 8: The pass rate at school would improve if learners in Umzimkhulu were taught in isiBhaca.

The respondents' 'mean score' was 3.98 in this belief statement, which indicates that they agreed with it. The finding is consistent with the one in Belief statement 6 in which the respondents believed that being taught through an HL (isiBhaca) would improve learners' performance in school.

There was an insignificant difference between female $($ mean $=4.14)$ and male $($ mean $=3.52)$ respondents, as both recorded 'mean scores' which showed that they agreed with the belief statement. The oldest group (14 years old) with a 'mean score' of 4.75 strongly agreed with the belief statement, while the youngest group (12 years old) with a 'mean score' of 3.98 and the middle group (13 years old) with a 'mean score' of 3.86 agreed with it.

Belief statement 11: Language rights of learners in Umzimkhulu are violated if they continue to be taught in isiXhosa or isiZulu and not in isiBhaca.

The purpose of this belief statement was to find out whether the respondents felt that their rights as learners in Umzimkhulu were violated, as they were taught in isiXhosa instead of isiBhaca. A 'mean score' of 4.13 indicated that they agreed with the belief statement. The reason why they felt this could be found in the fact that South Africa is a multilingual country whose Constitution guarantees language rights to every person. The respondents may have been aware of this fact; hence their belief that their language rights were violated.

Female $($ mean $=4.14)$ and male $($ mean $=4.07)$ respondents agreed with the belief statement. The oldest group (14 years old) with a 'mean score' of 4.50 was the only one which strongly agreed with the belief statement. The other two groups agreed with it (12 year old $=4.21$ and 13 years old $=4.04$ ).

TABLE 2: Using isiBhaca for educational purposes.

\begin{tabular}{|c|c|c|c|}
\hline Number & Belief statements & Mean scores & Aggregate attitudinal tendencies \\
\hline 5 & IsiBhaca is only relevant for discussing matters, such as lobola negotiations and not for educational purposes. & 2.20 & Disagree \\
\hline 6 & Learners in Umzimkhulu perform poorly in school because they are taught in isiXhosa or isizulu, and not in isiBhaca. & 3.96 & Agree \\
\hline 8 & The pass rate at school would improve if learners in Umzimkhulu were taught in isiBhaca. & 3.98 & Agree \\
\hline 11 & $\begin{array}{l}\text { Language rights of learners in Umzimkhulu are violated if they continue to be taught in isiXhosa or isiZulu, and } \\
\text { not in isiBhaca. }\end{array}$ & 4.13 & Agree \\
\hline - & Aggregate (for the category). & 3.57 & Agree \\
\hline
\end{tabular}

Source: Ditsele, T., 2014, 'Perceptions of Black South African languages: A survey of the attitudes of Setswana-speaking university students toward their first language', Doctoral thesis, Tshwane University of Technology, Pretoria 


\section{Summary of Category 1: Using isiBhaca in the education space}

From the four belief statements under this category, it is concluded that the respondents believed that isiBhaca was relevant beyond being used for cultural and traditional events, and that being taught in this language would see learners in Umzimkhulu improve their school performance. Their favourable attitudes towards isiBhaca were also reflected in their belief that not being taught through isiBhaca violated their constitutional right of being taught in their HL. There was an 'aggregate attitudinal tendency' of 3.57 for the category, which suggests that the respondents agreed with the notion of 'using isiBhaca for educational purposes'. An analysis of the 'mean score' illustrates that the two variables (viz. 'sex' and 'age') influenced the respondents' levels of agreement albeit to varying levels as far as Category 1 is concerned.

\section{Category 2: Recognising and developing isiBhaca}

As Table 3 shows, Belief statements 4, 7, 10 and 12 belong to this category.

Belief statement 4: isiBhaca should not be given official recognition because the people of Umzimkhulu use very few words that are different from those used in isiZulu or isiXhosa.

This belief statement sought to find out whether the respondents felt that isiBhaca should not be given official status in areas where it was spoken. With a 'mean score' of 2.77 , the respondents indicated that that they were not sure whether isiBhaca should be officially recognised or not.

There was an insignificant difference between male (mean = 2.98 ) and female (mean $=2.60)$ respondents, as both recorded 'mean scores' that showed they were not sure about the belief statement. The oldest respondents (14 years old) recorded a 'mean score' of 1.25 , thus strongly disagreed with the belief statement, while the other two groups were not sure about it (13 year old $=3.05$ and 12 years old $=2.54$ ).

Belief statement 7: Even if isiBhaca is related to isiXhosa or isiZulu, it should be developed as a separate language.

In this belief statement, the respondents scored a 'mean' of 3.90 , which indicates that they agreed with the suggestion that isiBhaca should be developed as a separate language, away from isiXhosa and isiZulu. A possible reason for being open to the idea of isiBhaca being developed as a separate language is that anecdotal evidence suggests that the isiBhaca people take pride in their culture and language, even if it is nonstandard and has no official recognition. At the moment, they currently find themselves being forced to study through isiXhosa and reading the material written in isiXhosa and isiZulu because they are developed languages and enjoy official status in South Africa.

Female $($ mean $=3.98)$ and male $($ mean $=3.78)$ respondents agreed with the belief statement. The youngest group (12 years old) and the middle group (13 years old) with 'mean scores' of 3.66 and 3.94, respectively, agreed with the belief statement, while the oldest group (14 years old) strongly agreed with it with a 'mean score' of 4.50 .

Belief statement 10: Developing study material in isiBhaca will be a waste of government resources.

In this belief statement, the aim was to establish whether the respondents thought that it would be a waste of time if government developed isiBhaca and provided study material in the language. A 'mean score' of 2.25 was recorded, which means that the respondents disagreed with the belief statement. Put differently, they believed that learners in Umzimkhulu would benefit from accessing study material in isiBhaca.

The spirit of the Constitution of South Africa is that of encouraging people to use their HLs where it is practical. This possibly explains why the respondents supported the idea to have academic resources being made available in isiBhaca, a move that would see it being developed. While this belief statement can also be classified under Category 1, the researchers felt that it should be discussed under Category 2 because it is primarily about 'language development' as opposed to 'language in education' (a secondary consideration).

Both male $($ mean $=2.43)$ and female $($ mean $=2.15)$ respondents disagreed with the belief statement. The oldest group (14 years old) with a 'mean score' of 1.25 strongly disagreed with the belief statement, while the other two groups disagreed with it (13 year old $=2.32$ and 12 years old $=2.22$ ).

Belief statement 12: isiBhaca should not be developed for use in any form of schooling (e.g. primary school, high school or university).

In this belief statement, the aim was to determine whether the respondents felt that isiBhaca should not be developed

TABLE 3: Recognising and developing isiBhaca.

\begin{tabular}{|c|c|c|c|}
\hline Number & Belief statements & Mean scores & Aggregate attitudinal tendencies \\
\hline 4 & $\begin{array}{l}\text { IsiBhaca should not be given official recognition because the people of Umzimkhulu use very few words that } \\
\text { are different from isiXhosa or isiZulu ones. }\end{array}$ & 2.77 & Not sure \\
\hline 7 & Even if isiBhaca is related to isiXhosa or isizulu, it should be developed as a separate language. & 3.90 & Agree \\
\hline 12 & IsiBhaca should not be developed for use in any form of schooling (e.g. primary school, high school or university). & 2.21 & Disagree \\
\hline - & Aggregate (for the category). & 2.78 & Not sure \\
\hline
\end{tabular}

Source: Ditsele, T., 2014, 'Perceptions of Black South African languages: A survey of the attitudes of Setswana-speaking university students toward their first language', Doctoral thesis, Tshwane University of Technology, Pretoria 
for use in any form of schooling. A 'mean score' of 2.21 was recorded, which implies that respondents disagreed with the idea of not introducing isiBhaca for the purposes of teaching and learning. In other words, they were of the opinion that isiBhaca should be developed for use in the education environment.

A possible reason for this stance is that even if isiXhosa is mutually intelligible with isiBhaca, the respondents may be of a belief that the ideal language to be used for educational purposes is a people's HL (isiBhaca in this case) and not an L2 (isiXhosa in this case). Just like in Belief statement 10, this belief statement can also be classified under Category 1. Likewise, the researchers felt that it should be discussed under Category 2 , because it is primarily about 'language development' as opposed to 'language in education' (a secondary consideration).

There was a negligible difference between female (mean = 2.23 ) and male (mean $=2.15$ ) respondents as both recorded 'mean scores' which showed that they disagreed with the belief statement. The middle group (13 years old) and the youngest group (12 years old) with 'mean scores' of 2.31 and 2.17 , respectively, disagreed with the belief statement, while the oldest group (14 years old) strongly agreed with it, with a 'mean score' of 1.25.

\section{Summary of Category 2: Recognising and developing isiBhaca}

From the four belief statements under this category, it is concluded that the respondents were of the view that isiBhaca should be developed for educational purposes and also as a separate language from isiXhosa and isiZulu, a move that would be beneficial to its L1 speakers, particularly learners. Nevertheless, they were not sure if this development should extend to isiBhaca being given official status, a stance which is reflected in an 'aggregate attitudinal tendency' of 2.78, which suggests that, overall, the respondents were uncertain when it comes to the 'recognition and development of isiBhaca. As far as Category 2 is concerned, an analysis of 'mean scores' illustrates that the two variables (viz. 'sex' and 'age') influenced the respondents' levels of agreement albeit to varying levels.

\section{Category 3: Matching isiBhaca against isiXhosa and isiZulu}

Belief statements 1, 2, 3 and 9 belong to this category and presented in Table 4.

Belief statement 1: The manner in which the people of Umzimkhulu speak is influenced by the area being in KwaZulu-Natal and close to the Eastern Cape.
An aggregate mean score of 4.48 shows that the respondents agreed that Umzimkhulu's location in KwaZulu-Natal and its close proximity to the Eastern Cape influenced how the people of this area spoke. This finding comes as no surprise because many people of Umzimkhulu speak isiBhaca - a non-standard variety which is mutually intelligible with both isiXhosa and isiZulu.

Female respondents recorded a higher 'mean score' of 4.57, which means that they strongly agreed with the belief statement, while male respondents (mean $=4.35$ ) agreed with it. The 'mean score' of the older group (14 years old) was 4.75, followed by the younger group (12 years old) at 4.52 , and then the middle group (13 years old) at 4.43. 'Age', in this regard, influenced the respondents' levels of agreement; the 'oldest group' strongly agreed, the 'youngest group' also strongly agreed, while the 'middle group' just agreed.

Belief statement 2: There is a big difference between isiBhaca and isiXhosa or isiZulu.

This belief statement sought to establish whether the respondents believed that there was a big difference between isiXhosa or isiZulu and isiBhaca. With a mean score of 2.50, this means that respondents were not sure about the belief statement. This finding is informed by the fact that when one compares isiBhaca with isiXhosa and isiZulu, it is found that the differences are not about lexical items, but how such lexical items are pronounced. That said, there are a few lexical items, which are different between isiBhaca and the two standard varieties.

Of the three 'ages', the youngest group (12 years old), with a 'mean score' of 2.47 , was the only group that disagreed with the belief statement; the other two groups were not sure about it.

Belief statement 3: isiBhaca is close to isiXhosa, but not to isiZulu.

This belief statement was asked to find out if the respondents believed whether isiBhaca was more closely related to isiXhosa than it was to isiZulu. The mean score of 2.51 was scored and it indicates that they were not sure about it. This uncertainty in deciding the linguistic distance between isiBhaca and the other two languages lies in the fact that they were taught isiXhosa at school while residing in Umzimkhulu, which is located in KwaZulu-Natal, a province whose dominant language is isiZulu.

Male respondents scored a 'mean score' of 2.73, while female respondents scored a 'mean score' of 2.40 , which means that

TABLE 4: Matching isiBhaca with isiXhosa and isiZulu.

\begin{tabular}{llll}
\hline Number & Belief statements & Mean scores & Aggregate attitudinal tendencies \\
\hline 1 & $\begin{array}{l}\text { The manner in which the people of Umzimkhulu speak is influenced by the area being in KwaZulu-Natal and } \\
\text { close to the Eastern Cape. }\end{array}$ & 4.48 \\
\hline 2 & There is a big difference between isiBhaca and isiXhosa or isiZulu. & Agree \\
3 & IsiBhaca is close to isiXhosa, but not to isiZulu. & 2.50 & Not sure \\
9 & IsiBhaca is close to isiZulu, but not to isiXhosa. & Not sure & Not sure \\
- & Aggregate (for the category). & 2.51 & Not sure \\
\hline
\end{tabular}

Source: Ditsele, T., 2014, 'Perceptions of Black South African languages: A survey of the attitudes of Setswana-speaking university students toward their first language', Doctoral thesis, Tshwane University of Technology, Pretoria 
the former were not sure about the belief statement, while the latter disagreed with it. With a 'mean score' of 1.79 , the middle group (13 years old) was the only one which disagreed with the belief statement; the other two groups (12 years old at 2.88 and 14 years old at 2.75) were not sure about it.

Belief statement 9: isiBhaca is close to isiZulu, but not to isiXhosa.

A mean score of 2.82 indicates that the respondents were not sure as to whether isiBhaca was closer to isiZulu than it was to isiXhosa. As with Belief statement 3, the presence of both isiXhosa and isiZulu in their surroundings made it difficult for them to lean towards either of the two standard varieties.

There was a negligible difference between female (mean = 2.88 ) and male (mean $=2.77$ ) respondents as both recorded 'mean scores' which showed that they were not sure about the belief statement. The oldest group (14 years old) with a 'mean score' of 1.75 disagreed with the belief statement, while the other two groups were not sure about it (13 year old $=3.25$ and 12 years old $=2.75$ ).

\section{Summary of Category 3: Matching isiBhaca against isiXhosa and isizulu}

With an 'aggregate attitudinal tendency' of 3.08 for the category, a conclusion could be reached that the respondents were not sure as to which between isiXhosa and isiZulu was linguistically closer to isiBhaca. An analysis of the mean score shows that the two variables (viz. 'sex' and 'age') influenced the respondents' level of agreement albeit to varying levels, as far as Category 3 is concerned.

\section{Qualitative data}

Eight questions were put to 128 learners who were asked to answer YES or NO first, followed by a 'motivation' for their choice of answer. Answers to the eight questions were also split into the three categories presented in the section above. In analysing the data, we used percentages to illustrate the frequencies of the respondents' answers, followed by prominent reasons they provided as motivation for the reasons they advanced. It is also important to note that their motivations were grouped for the purposes of coherence.

\section{Category 1: Using isiBhaca in the education space}

Questions 1, 2, 6 and 7 belong to this category and they are discussed below.

Question 1: Do you think that learners in Umzimkhulu do not perform well because they are taught in isiXhosa or isiZulu instead of in isiBhaca? An overwhelming majority of the respondents $(75 \%)$ thought that learners in Umzimkhulu did not perform well because they were not taught in isiBhaca, but isiXhosa or isiZulu. The most common reason they gave was that 'isiBhaca is a language we speak at home, thus would understand school work far much better in it'. The second most common reason they gave was that
'isiXhosa is not the best language we express ourselves in, thus we struggle a bit to understand school work'.

A minority of them (25\%) did not believe that learning through isiXhosa or isiZulu affected Umzimkhulu's learners. The most common reason they presented was 'we are used to isiXhosa because our education is given through the language when we start school'.

Question 2: Do you think that results of learners in schools in Umzimkhulu would improve if learners were taught in isiBhaca? An overwhelming majority of the respondents (86.7\%) believed that learners' results in Umzimkhulu would improve were they to be taught in isiBhaca. The most common reason they provided was the one they gave in Question 1, that is, isiBhaca was a language they speak at home, thus would understand school work much better in it.

Likewise, a minority of them (13.3\%), who believed that results would not improve were they to be taught in isiBhaca, also provided the most common reason that they started school being taught in isiXhosa, thus they were used to this language.

Question 6: Do you think that adults in your family would encourage you to study isiBhaca should it be taught at your school? A majority of the respondents $(67.2 \%)$ believed that adults in their families would encourage them to study isiBhaca were this language to be taught at their school. Being L1 speakers of isiBhaca was the main reason given by many of them. A few others stated that adults in their families knew that they did not speak isiXhosa and isiZulu well, thus would be in favour of learners in Umzimkhulu being taught in isiBhaca.

A minority of the respondents (32.8\%) were of the view that adults in their families would not encourage them to study isiBhaca if it were taught at their school. Many of these respondents came from families where isiXhosa and isiZulu were spoken as HLs, thus were not open to the status quo being challenged. In addition, they stated that adults in their families held negative attitudes towards isiBhaca.

Question 7: Should your school introduce isiBhaca next year, would you advise learners in Umzimkhulu to continue to study isiXhosa or isiZulu? Around a quarter of the respondents $(25.8 \%)$ stated that they would advise learners in Umzimkhulu to continue to study in isiXhosa and isiZulu even if their school introduced isiBhaca the following year. The most prominent reason they provided was that the status quo should be maintained because learners were already used to being taught in isiXhosa and isiZulu, thus replacing them with isiBhaca would create confusion. The less prominent reason was that they did not like isiBhaca.

Nearly three-quarters of the respondents (73.2\%) stated that they would discourage learners in Umzimkhulu to continue to study in isiXhosa and isiZulu if isiBhaca were to be introduced at their school the following year. The most 
prominent reason they gave was that it was only fair and logical to introduce isiBhaca in the education space because most families spoke the language at home, as opposed to isiXhosa and isiZulu. The less prominent reason they mentioned was that the introduction of isiBhaca at their school would stop the violation of their constitutional right to be taught their HL at school.

\section{Summary of Category 1: Using isiBhaca in the education space}

From the four questions presented above under this category, a conclusion could be reached that an overwhelming majority of the respondents believed that there would be enormous benefits for using isiBhaca in the education space in Umzimkhulu. This finding is consistent with ones made in Belief statements 6, 8 and 11 .

\section{Category 2: Recognising and developing isiBhaca}

The discussion below focuses on Questions 3 and 4, which belong to this category.

Question 3: Do you think that government should develop study material in isiBhaca so that isiBhaca speakers can use it in school? An overwhelming majority of the respondents (78.9\%) were of the view that government should develop study material in isiBhaca for use at schools where there are HL speakers of the language. One of the prominent reasons they provided was that such a move would allow HL speakers to enjoy the constitutional right of learning in their language at school, like many other people whose HLs were accessible at school.

A minority of them (21.1\%) thought that it would not be a great idea to develop study material in isiBhaca for use at school. One of the prominent reasons they submitted was that it was too late in the day to go this route because over many years, learners in Umzimkhulu had been taught isiXhosa and government had already invested a lot of money in the development of this language.

Question 4: Do you think that isiBhaca should be officially recognised in areas where many people speak it, for example, in the provinces of KwaZulu-Natal and the Eastern Cape? An overwhelming majority of the respondents (84.4\%) thought that isiBhaca should be officially recognised in the provinces of KwaZulu-Natal and the Eastern Cape, where the language was spoken by many people. Many respondents submitted that the language's official recognition in the two provinces would be a step in the right direction, one which has the potential to it being introduced at schools. A few others reiterated the notion of 'language rights' enshrined in the Constitution; they stressed that continuing to ignore that isiBhaca is a people's language violates its speakers' constitutional rights.

A small minority of the respondents (15.6\%) were opposed to the idea. Some of them noted that the percentage of HL speakers of isiBhaca was so low in the two provinces that it would not make sense to grant it official status.

\section{Summary of Category 2: Recognising and developing isiBhaca}

Responses to Questions 3 and 4 suggest that the respondents overwhelmingly supported the recognition and development of isiBhaca, while a small minority of respondents were not supportive of the idea. There is consistency between Belief statement 10 and Question 3. In Belief statement 10, the respondents disagreed that developing study material in isiBhaca will be a waste of government resources, while in Question 3, they overwhelmingly (78.9\%) thought that government should develop study material in isiBhaca so that isiBhaca speakers can use it at schools. This consistency can be extended to Belief statement 12, where the respondents disagreed with the suggestion that isiBhaca should not be developed for use in any form of schooling (e.g. primary school, high school or university). Put differently, they supported the idea to develop the language for use at all levels of formal education, that is, from primary school up to university.

There is a discrepancy between their response to Belief statement 4 and Question 4 on whether isiBhaca should be granted official status or not. A major difference between the two lies in being general as opposed to being specific. In Belief statement 4 , the respondents were not sure on whether isiBhaca should be granted official status, perhaps because the belief statement was general, thus they may have thought about 'official status' at a national level. However, Question 4 specifically focused on the provinces of KwaZulu-Natal and the Eastern Cape and their responses were overwhelming $(84.4 \%)$ that isiBhaca should be granted official status.

\section{Category 3: Matching isiBhaca against isiXhosa and isiZulu}

Questions 5 and 8 belong to this category and they are discussed below.

Question 5: Do you think that there is a difference between isiBhaca and isiZulu? An overwhelming majority of the respondents $(95.3 \%)$ were of the view that there were differences between isiBhaca and isiZulu, which upon inspection were at the morphological and phonological levels. They submitted some differences that are provided in Table 5.

A small minority of the respondents (4.7\%) thought that there were no differences between isiBhaca and isiZulu.

Question 8: Do you think that there is a difference between isiBhaca and isiXhosa? An overwhelming majority of the respondents $(94.5 \%)$ noted that there were differences between isiBhaca and isiXhosa, which under scrutiny were at the lexical, morphological and phonological levels. In fact, some of them noted that the manner in which they pronounced words in the two languages was not the same. They submitted some differences that are provided in Table 6 . 
TABLE 5: Differences between isiBhaca and isiZulu.

\begin{tabular}{lll}
\hline isiBhaca & IsiZulu & English equivalents \\
\hline Andati & Angazi & I do not know \\
Edasi & Ezansi & Down there \\
Khamba or ukukhamba & Hamba or ukuhamba & Walking or going \\
Ndiyakhuphuka & Ngiyakhuphuka & To walk up \\
Ngesheya & Ngaphesheya & Over there (across) \\
\hline
\end{tabular}

TABLE 6: Differences between isiBhaca and isiXhosa.

\begin{tabular}{lll}
\hline isiBhaca & isiXhosa & English equivalents \\
\hline Bekuhum & Bekundim & It was me \\
Bheka & Jonga & To look \\
Leyanto & Lanto & Thing \\
Ndiyakhamba & Ndiyahamba & I am going or leaving \\
Ndiyakutshena & Ndiyakuxelela & I am telling you \\
Ndiyawatsha & Ndiyahlamba & I am washing \\
Hukudla & Ukutya & Food \\
Huyisiphukuphuku & Usisibhanxa & You are stupid \\
Layo or lana & Apho or apha & There \\
Shuba & Ggqiba & To finish \\
Tshetsha & Khawuleza & Hurry up \\
\hline
\end{tabular}

A small minority of the respondents (5.5\%) held a view that there were no differences between isiBhaca and isiXhosa.

\section{Summary of Category 3: Matching isiBhaca against isiXhosa and isiZulu}

The respondents recorded very high percentages (viz. more than $94 \%$ for Questions 5 and 8) in arguing that there were differences between isiBhaca and isiZulu, and isiBhaca and isiXhosa. They also provided examples of such differences as illustrated in Tables 5 and 6 . They provided far more examples of the differences between isiBhaca and isiXhosa as opposed to the differences between isiBhaca and isiZulu because all of them studied isiXhosa at school.

In comparing these findings made in Belief statements 3 and 9 against Questions 5 and 8, one notices that in the belief statements, the respondents were not sure as to whether isiBhaca was closer to isiXhosa compared to isiZulu and vice versa. One may think that there are contradictions between the two belief statements when contrasted with the two questions. However, they do not contradict each other, because in the belief statements, the respondents were asked to gauge as to which between isiXhosa and isiZulu was closer to isiBhaca than the other, and they indicated that they were not sure. In other words, they were asked to directly match isiXhosa against isiZulu relative to isiBhaca. One respondent made this interesting remark and stated that when they are with Zulus, they say that he or she is Xhosa, but when they are with Xhosas, they say he or she is Zulu.

When it comes to Questions 5 and 8, the respondents were not asked to match isiXhosa against isiZulu, but to focus on each language at a time, as it relates to isiBhaca. That fundamental difference saw them being unequivocal that there were lexical, morphological and phonological differences between isiBhaca and isiZulu, as well as between isiBhaca and isiXhosa.

\section{Conclusion}

As indicated in the study's introduction, we sought to establish learners' attitudes towards the recognition and development of isiBhaca in the education space in Umzimkhulu. Having analysed and discussed the study's quantitative and qualitative data, we now provide answers to our research questions.

Firstly, we sought to establish whether learners held positive or negative attitudes towards the introduction of isiBhaca in their education; our conclusion is that they held positive attitudes towards isiBhaca. Secondly, we sought to establish whether they believed that the introduction of isiBhaca in their education would be beneficial or detrimental to the same, as opposed to the retention of isiXhosa and isiZulu in their education; we conclude that they believed that the introduction of isiBhaca would be beneficial to their education. Thirdly, we sought to establish whether they were conscious about language rights as they pertain to isiBhaca being recognised and developed for the purposes of learning; our conclusion is that they were conscious about language rights and held views that HL speakers of isiBhaca were denied such rights.

Beyond these conclusions, it is worthwhile to note minority views. The study comprised $20.3 \%$ of the respondents whose HLs were isiXhosa and isiZulu, against $79.7 \%$ of those whose HL was isiBhaca. Evidently, HL speakers of isiXhosa and isiZulu felt threatened by the notion of introducing isiBhaca in education because such a move would threaten the current status quo of their HLs being favoured over isiBhaca in education; they would prefer that things remain as they are.

\section{Future research}

We move from a premise that researchers should establish from HL speakers about the status of their language, that is, is it a language in its own right or a dialect of another language. In the case of isiBhaca, its HL speakers hold a view that it is neither a dialect of isiXhosa nor of isiZulu, but a language in its own right, which, as an Nguni language, is mutually intelligible with the latter two languages. Language is a sensitive matter, and dictating to speakers that their HL is a 'dialect or 'non-standard variety' which is not an acceptable language in formal and significant domains, can only alienate them and build resentment towards the 'standard variety' being imposed upon them.

Moving from a premise that learners in Umzimkhulu expressed an appetite for the recognition and development of isiBhaca, we are of the view that future research needs to be conducted on the feasibility of developing isiBhaca to be a language that could be used in education. Such future research may be beneficial to other languages having no recognition as languages in their own right.

\section{Acknowledgements}

The authors wish to express their sincere appreciation to the 128 respondents (Grades 6 and 7 learners) from Umzimkhulu who participated in this research study. 


\section{Competing interests}

The authors declare that they do not have any financial or personal relationships that may have inappropriately influenced them in writing this article.

\section{Authors' contributions}

This article was written out of Mr Y.L.P. Majola's Master's research project under the supervision of Dr T. Ditsele, and co-supervision of Prof. M. Cekiso. Mr Y.L.P. Majola drafted the article, while Dr T. Ditsele and Prof. Cekiso revised and finalised it.

\section{Funding information}

This research received no specific grant from any funding agency in the public, commercial or not-for-profit sectors.

\section{Data availability statement}

Data sharing is not applicable to this article.

\section{Disclaimer}

The views and opinions expressed in this article are those of the authors and do not necessarily reflect the official policy or position of any affiliated agency of the authors.

\section{References}

Ajzen, J., 1988, Attitude, personality and behaviour, Open University Press, Milton Keynes. Babich, R.M., 1987, 'Dialects in the classroom: Their functions, some potential problems and guidelines for teachers', Journal of Thought 22(4), 89-94.

Ball, J., 2010, Enhancing learning of children from diverse language backgrounds: Mother tongue-based bilingual or multilingual education in the early years, UNESCO, Paris.

Ball, J., 2014, Children learn better in their mother tongue: Advancing research on mother tongue-based multilingual education, Global Partnership for Education viewed 18 March 2019, from https://www.globalpartnership.org/blog/childrenlearn-better-their-mother-tongue.

Bernard, H.R., 2002, Research methods in anthropology: Qualitative and quantitative approaches, Third Alta Mira Press, Walnut Creek, CA.

Butzkamm, W., 2003, 'We only learn language once: The role of the mother tongue in FL classrooms: Death of a dogma', Language Learning Journal 28(1), 29-39. https://doi.org/10.1080/09571730385200181

Cheshire, J., 2005, 'Sociolinguistics and mother-tongue education', in U. Ammore, N. Dittnur, K. Mattheier \& P. Trudgill (eds.), Sociolinguistics: An introductory handbook of the science of language and society, 2 nd edn., pp. 2341-2350, Mouton de Gruyter, Berlin.

Cook, G., 2003, Applied linguistics, Oxford University Press, Oxford.

Creswell, J.W. \& Plano Clark, V.L., 2011, Designing and conducting mixed method research, SAGE, Thousand Oaks, CA.

Cummins, J., 2000, Language, power and pedagogy: Bilingual children in the crossfire, Multilingual Matters, Clevedon.
Ditsele, T., 2014, 'Perceptions of Black South African languages: A survey of the attitudes of Setswana-speaking university students toward their first language', Doctoral thesis, Tshwane University of Technology, Pretoria.

Downes, W., 1998, Language and society, 2nd edn., Cambridge University Press, Cambridge.

Dumitraskovic, T.A., 2014, 'Culture, identity, and foreign language teaching and learning', Journal of Foreign Teaching and Learning 3(2), 251-258. https://doi. org/10.14706/JFLTAL152222

Dunstan, S.B., 2015, 'Dialect and influences on the academic experiences of college students', The Journal of Higher Education 86(5), 777-803. https://doi.org/ 10.1353/jhe.2015.0026

Foley, A., 2001, Mother-tongue education in South Africa, viewed 18 March 2019, from https://pdfs.semanticscholar.org/7480/e45690cf7819b8e19de46fb050dbf5 da3231.pdf

Garrett, P., Coupland, N. \& Williams, A., 2003, Investigating language attitudes: Social dialect, ethnicity and performance, pp. 1-251, University of Wales Press, Cardiff.

Giles, H. \& Johnson, P., 2006, 'Language attitudes and the role of communication infrastructures: Communication ecology model', Moderna Spŕak 100(1), 38-54.

Gxilishe, D.S., 1996, 'The dilemma of dialect in the classroom: A case for Xhosa', Per Linguam 12(1), 1-14. https://doi.org/10.5785/12-1-208

Johnson, R.B. \& Turner, L.S., 2003, 'Data collection strategies in mixed methods research', in A. Tashakkori \& C. Teddlie (eds.), Handbook of mixed methods in social and behavioral research, SAGE, Thousand Oaks, CA.

Kramer, C.E., 2004, 'Accommodating dialect speakers in the classroom: Sociolinguistic aspects of textbook writing', Canadian Slavonic Papers 46(1-2), 59-72. https:// doi.org/10.1080/00085006.2004.11092346

Lippi-Green, R., 2012, English with an accent: Language, ideology, and discrimination in the United States, Routledge, London.

Malone, S., 2007, Mother tongue-based multilingual education, viewed 06 Septembe 2018, from https://www.sil.org/sites/default/files/files/mtbmle_implications _ for_policy.pdf.

Maqam, E.Z., 2015, 'The experiences of isiMpondo speakers in learning standard isiXhosa through the formal education system: An exploratory study at a school in the Bizana district of the Eastern Cape', Master's dissertation, Rhodes University, Grahamstown.

McMillan, J.H. \& Schumacher, S., 2010, Research in education: Evidence-based inquiry, 7th edn., pp. 1-528, Pearson, Boston, MA.

Mtsatse, N. \& Combrinck, C., 2018, 'Dialects matter: The influence of dialects and code-switching on the literacy and numeracy achievements of isiXhosa Grade 1 learners in the Western Cape', Journal of Education 72, 20-37. https://doi. org/10.17159/2520-9868/i72a02

Nomlomo, V.S., 1993, 'Language variation in the Transkeian Xhosa speech community and its impact on children's education', Master's dissertation, University of Cape Town, Cape Town.

Papapavlou, A. \& Pavlou, P., 2007, Sociolinguistic and pedagogical dimensions of dialects in education, Cambridge Scholars Publishing, Newcastle.

Perloff, R.M., 1993, 'Third-person effect research 1983-1992: A review and synthesis', International Journal of Public Opinion Research 5(2), 167-184. https://doi. org/10.1093/ijpor/5.2.167

Republic of South Africa, 1996, Constitution of the Republic of South Africa (Act 108 of 1996), Republic of South Africa, Pretoria.

Republic of South Africa, 1997, Language in Education Policy, Republic of South Africa, Pretoria.

Sailzmann, Z., 2007, Language, culture and society, 7th edn., Westview Press, Boulder, CO.

Sigcau, N.E., 1998, 'Educational implications of non-standard varieties of Xhosa', Master's dissertation, University of Cape Town, Cape Town.

Spofana, D.G., 2011, 'Learners' texts: A portrayal of the influence of certain varieties of isiXhosa on English texts and vice versa', Doctoral thesis, University of South Africa, Pretoria.

Tegegne, W., 2015, 'The use of dialects in education and its impacts on students' learning and achievements', Educational Journal 4(5), 263-269. https://doi. org/10.11648/j.edu.20150405.22

The United Nations Educational, Scientific and Cultural Organization (UNESCO), 2008, Mother tonque matters: Local language as a key to effective learning, UNESCO, Paris. 